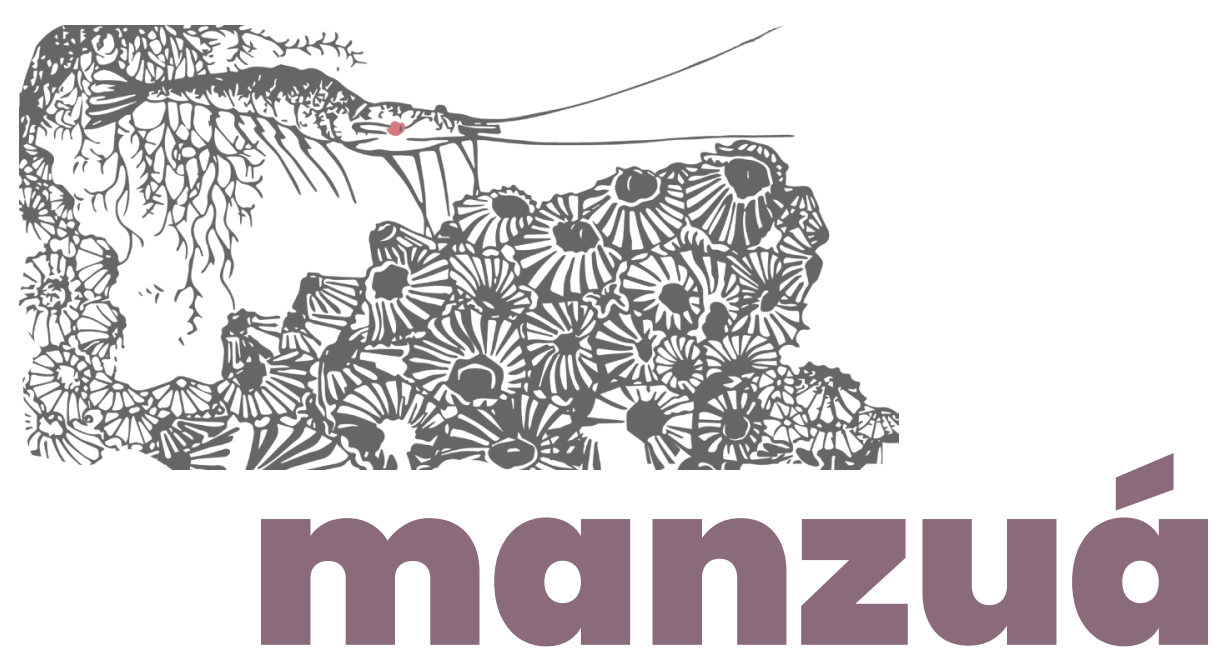

\title{
A TERRA SUBTIL
}

\section{Resumo:}

Vivemos tempos estranhos e ameaçadores. Pandemia e alterações climáticas são suficientemente graves para nos deixar numa perplexidade sem nome. Como descrever o que se está a passar nos múltiplos planos em que se desdobram as nossas subjectividades? Que aconteceu aos nossos corpos e aos nossos afectos? À nossa potência de vida?

Pensamos numa hipótese - experimentar cruzar a mudança radical dos nossos hábitos e mentalidades com a transformação dos sistemas sociais, agindo todos juntos, acreditando noutra coisa - na Terra.

Palavras-chave: corpo, terra, alterações climáticas, pandemia

\section{Abstract:}

We live in strange and threatening times. Pandemic and climate change are serious enough to leave us in a nameless perplexity. How to describe what is happening in the multiple planes in which our subjectivities unfold? What happened to our bodies and our affects? To our power of life?

We think of a hypothesis - trying to cross the radical change in our habits and mentalities with the transformation of social systems, acting all together, believing in something else - in Earth.

Keywords: body, earth, climate change, pandemic. 


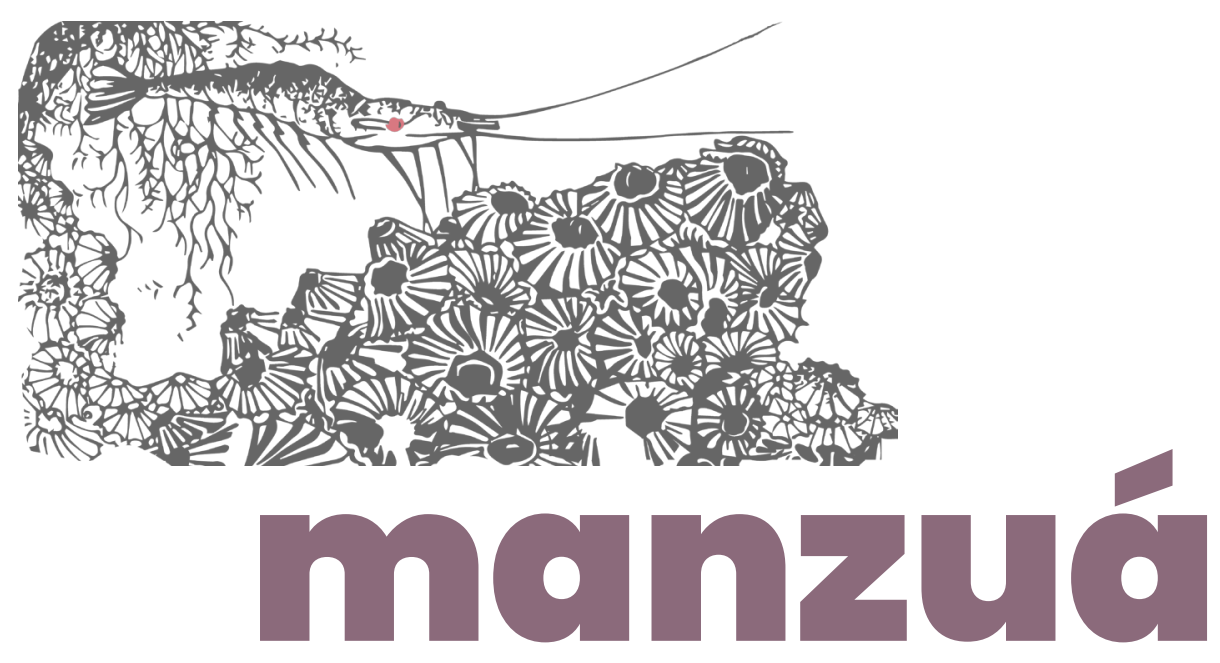

\section{Résumé:}

Nous vivons à une époque étrange et menaçante. La pandémie et les changements climatiques sont suffisamment graves pour nous plonger dans une perplexité sans nom. Comment décrire ce qui se passe dans les multiples plans où se déploient nos subjectivités ? Qu'est-il arrivé à nos corps et à nos affects ? Qu'est-elle devenue notre puissance de vie?

Nous pensons à une hypothèse - essayer de croiser le changement radical de nos habitudes et mentalités avec la transformation des systèmes sociaux, agir ensemble, croire à autre chose, à la Terre.

Mots clés : corps, terre, changement climatique, pandémie. 


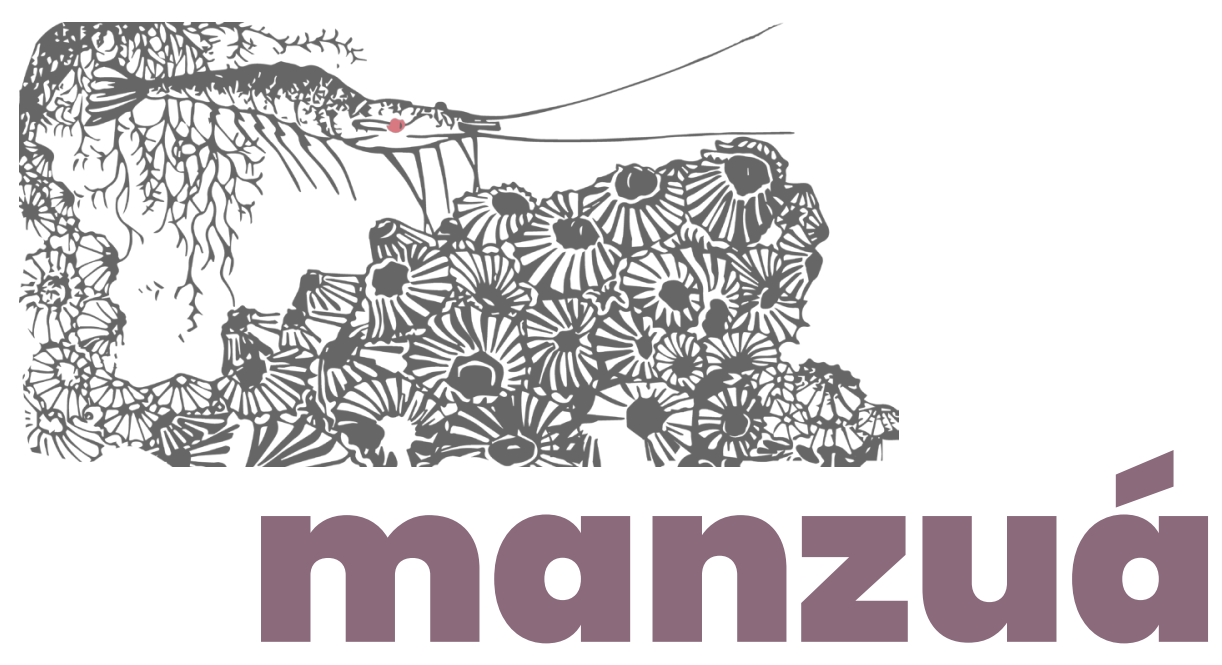

"Vivemos tempos estranhos" é a frase ouvida e repetida tantas vezes numa quase consciência que impede a análise do seu significado. Agora mesmo sente-se essa estranheza quando o silêncio da cidade ou do sítio se estende até ao som mais ínfimo. Quando o ar que se respira pode ir sem receio até ao fundo, ao mais recôndito lugar dos pulmões. Sente-se na distância de um pequeno passo que se alarga num tempo nunca antes visto. Sente-se por um certo formigar que desapareceu e na sensação de suspensão inquietante entre duas Histórias, uma de um tempo regular porque já vivido e outra de um futuro imprevisível.

Sem confusão, no momento presente, a conclusão parece evidente - o que se anuncia ou está prestes a chegar, ou já chegou, dá demasiados sinais de destruição e extinção. António Guterres, Secretário Geral da ONU defendeu recentemente que os Estados "devem agir juntos face à ameaça climática", que é "muito mais grave do que a pandemia em si". "É uma ameaça existencial para o planeta e para as nossas próprias vidas", insistiu'.

Destruímos o nosso elo com a terra como estamos a destruir, talvez, a nossa capacidade de nos regenerar. A transformação das forças económicas e dos sistemas de poder que atacam a terra, não é salvaguarda se não mudarmos radicalmente as nossas subjectividades anestesiadas. É neste plano que nos situamos agora. 


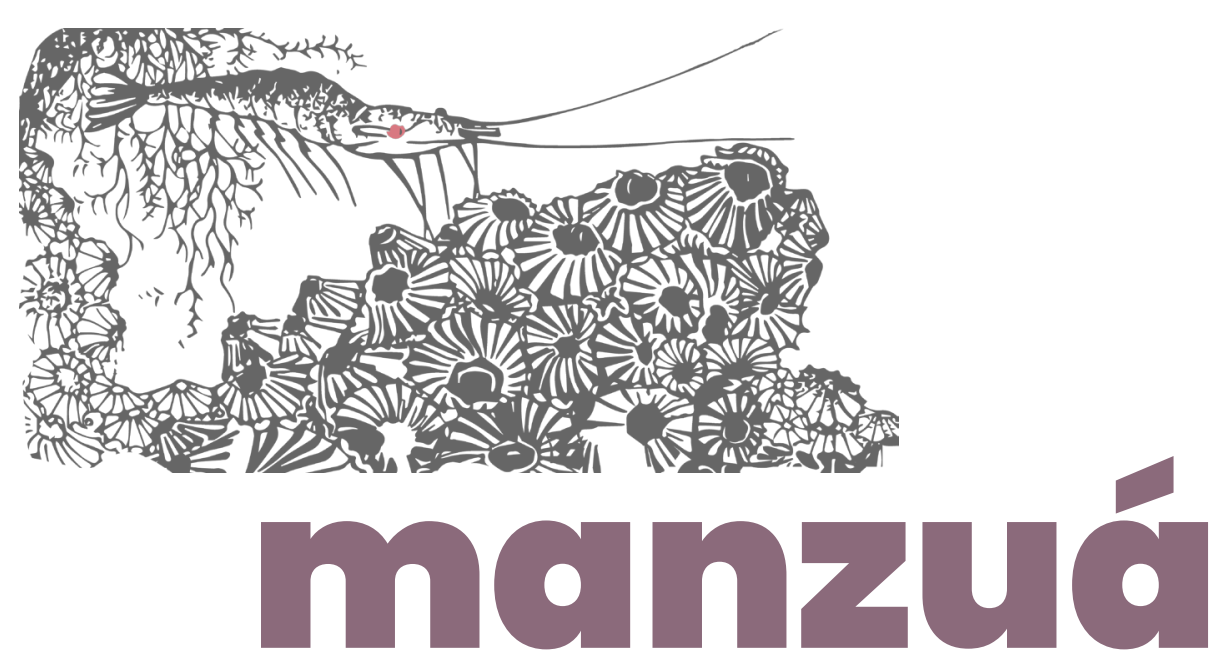

Vivemos num planeta que olha todos os dias para números de mortes, de infectados, de suspeitos com sintomas sugestivos, que sobem ou descem como noutros momentos catastróficos da história. Gráficos e estudos estatísticos propagam-se como a doença e, no limite, nada nos dizem do que realmente queremos saber. Para onde quer que olhemos, o que vemos são lugares e mais lugares onde os "sistemas de saúde" procuram até à exaustão cuidar dos vivos. Ao mesmo tempo, assistimos a acções políticas "light", levianas, omissas e inconsequentes, que parecem ignorar ou negligenciar a urgência do instante (em nome de qualquer coisa que não se diz e obscurece o que está a acontecer). Olhamos também para a economia, para a vida comunitária que desabam a cada confinamento, a cada dúvida ou falta de confiança e medo.

Diz-se quase todos os dias que sair do dilema é procurar salvar as pessoas e simultaneamente a economia. Talvez seja um falso dilema.

A dimensão da exposição à catástrofe (pandemia e alterações climáticas) é ainda desconhecida. Sabemos de alguns efeitos que parecem estabelecer relações de contaminação entre uma e outra - a via intermédia de transmissão do vírus e a desflorestação global ou o lixo pandémico e o solo, o isolamento social e a menor poluição atmosférica, por exemplo. Mas é cedo para sabermos qual o impacto real na saúde, nas relações sociais, no quotidiano, na cultura global, nos corpos. A gravidade dos problemas aparecerá ainda e transformará a terra, os modos de vida, os comportamentos e o pensamento.

Partimos de perturbações diversas - doenças, mortes, sofrimento, medos - todas complexas e familiares, vindas de outros corpos e de outros tempos. A memória que temos e teremos confrontanos com um vivido actual e uma antecipação que parecem muito 


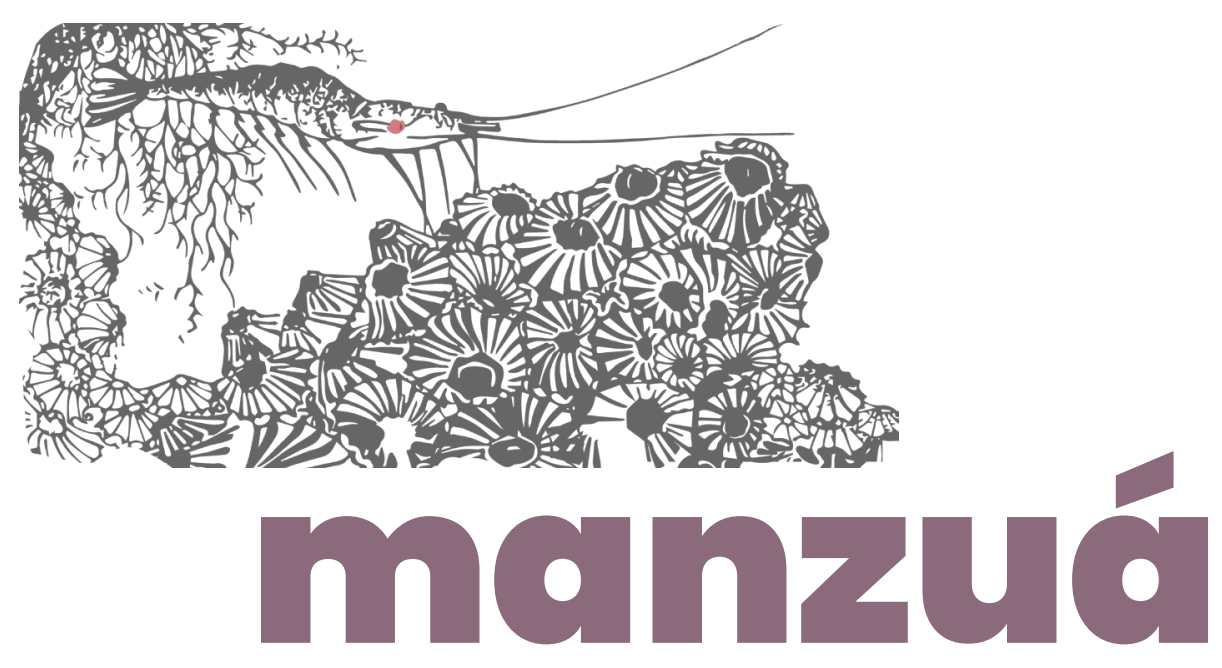

mais perigosos e não menos ameaçadores. Somos colonizados em todos os instantes e, por múltiplos meios, obrigados a viver um mesmo intolerável. Os riscos de voltarmos a viver acontecimentos semelhantes e outros mais extremos são enormes e parecem muito mais frequentes, acelerados e intermináveis. Os medos actualizamse, as catástrofes acumulam-se, instalam-se na duração e tornam-se banalidades universais. Uma espécie de violência sem fim trabalhanos e molda-nos o cérebro, o sistema imunitário, as respostas que damos - o corpo.

As respostas de sobrevivência que temos à mão são excepcionais, decorrem de estratégias condicionadas pelos constrangimentos (do meio envolvente hostil ou por quaisquer obstáculos internos) - confinamo-nos, isolamo-nos, anestesiamo-nos, dissociamonos. As nossas condutas de evitamento e tentativa de controle para não desencadear males maiores parecem inúteis ou são ineficazes. Tentamos escapar, mas o sofrimento avança de forma exponencial. Os nossos comportamentos ajustam-se, modificamse, não são auto-destrutivos (e não é que muitas vezes a vontade não o deseje). São antes de mais, tentativas desesperadas de querer viver, estratégias solitárias, atomizadas, dispersas, a par de outras estratégias colectivas que procuram também soluções protetoras. Todas parecem precárias e avançam ou recuam passo a passo. Tacteamos muito a esmo e às cegas.

O sofrimento incontrolável, e impossível de circunscrever, dissimulase muito facilmente, e muitos de nós ainda não conseguem imaginar nem compreender o que está a acontecer aceleradamente ao planeta, aos animais, aos vegetais, aos minerais, à vida. O que está a acontecer é global e é da nossa exclusiva responsabilidade 


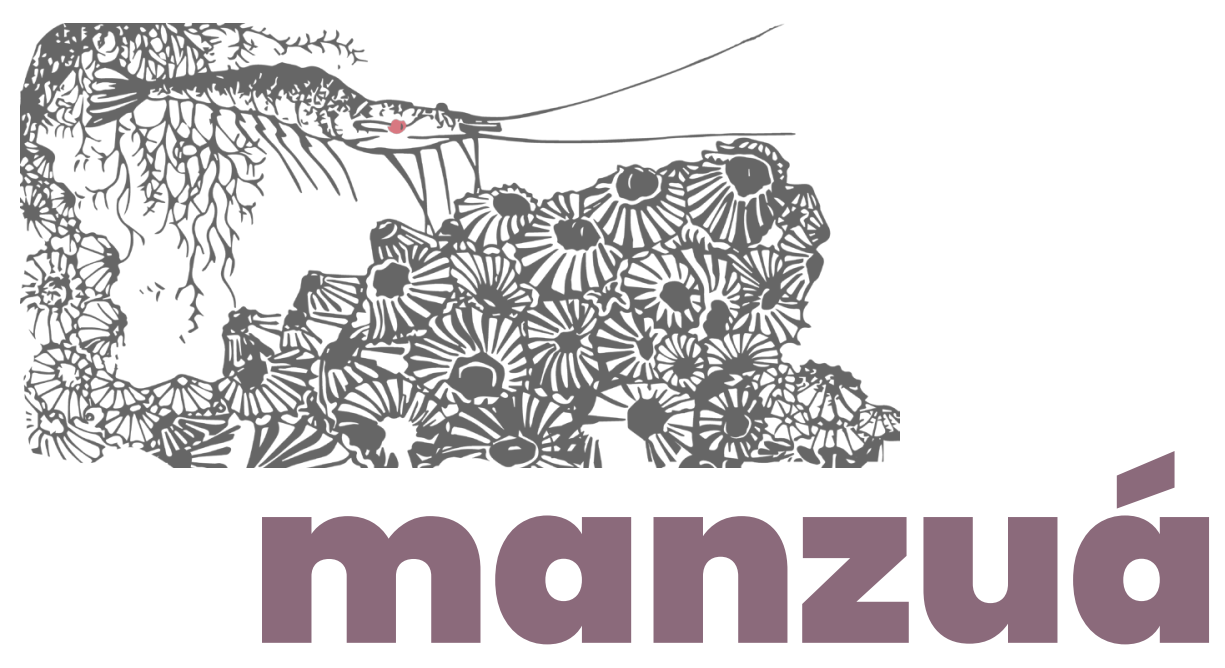

(colectiva e individual). Sabemos e compreendemos um pouco, quando o vivemos na pele, quando sentimos a erosão, o desgaste, o esgotamento das forças vitais. Quando sentimos na primeira pessoa a tristeza, o desespero e o terror, quando se repetem indefinidamente as mesmas dores. Sabemos que não deixámos de sofrer e que os estados de equilíbrio são cada vez mais raros e longínquos. Por pouco confiáveis que sejam as estatísticas, sentimos todos os dias, com a ajuda da ciência, que o ponto de não retorno se aproxima. As violências imparáveis não se conseguem tornar normais ou universais, nem duram para sempre.

Deveríamos conseguir integrar, explícita e claramente, tudo isto para podermos reparar e fazer desaparecer as estratégias de sobrevivência. O que significaria que elas não seriam mais necessárias. Porque são somente as soluções disponíveis, transitórias, face ao extremo. Reparar (o planeta e as nossas próprias vidas) parece ainda possivel, é sempre possivel recuperar e encontrar ou descobrir um sentimento real de coerência e de junção. Não tenho a certeza. Mas, tomar a cargo o que está a acontecer e compreender a gravidade da situação é mais do que uma possibilidade real, tem de ser uma experimentação necessária e imediata. Tomar, com determinação absoluta, para si e para o planeta inteiro, o corpo que nunca está no presente, mas, imanente, é capaz de conter o antes e o depois, a fadiga, a expectativa e até o desespero.

É verdade que há um efeito de sideração que paralisa, impede ou condiciona as reacções integradas, adaptadas, a produção de soluções pensadas e efectivamente reparadoras. A tempestade não parece acalmar, invade o planeta inteiro (são doenças, incêndios, furacões, degelos oceânicos, políticas devastadoras, atentados). 


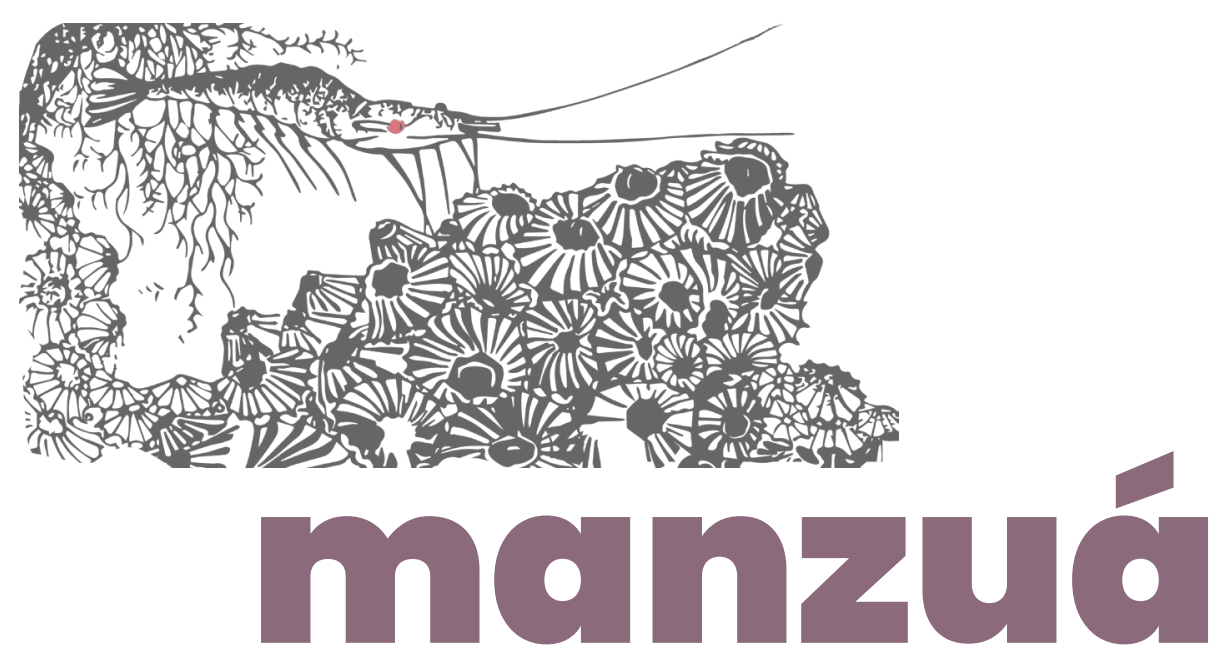

Diante do risco iminente, a Terra, como um corpo, inevitavelmente responde, mas desencadeia também, simultaneamente, mecanismos de salvaguarda que disjuntam circuitos, criando um efeito de anestesia geral que nos torna a todos estrangeiros, desintegrados, desconectados, despersonalizados. Somos esmagados e não conseguimos respirar, paralisamos com o embate - a cada segundo, um grão de areia na engrenagem, um joelho em cima do pescoço, partículas finas no ar, um tiro nas costas, um vírus que saiu da floresta que já não existe.

Somos, ao mesmo tempo, afectados e espectadores impotentes, e a partir de um certo momento começamos a perceber sem emoções o que se está a passar. A disjunção afectiva e mental que nos atinge isola-nos, impede-nos de sermos responsáveis, parece tornar-nos incapazes para recuperar o mais básico e vital. Torna-nos amnésicos, sem recordações, com o fantasma da morte e a própria morte a atravessarem todo o processo de criação. Não temos mais querer, não temos mais memória, nem controlo, caímos numa armadilha que nos põe fora do espaço e fora do tempo. Não conscientes, entramos em Loop - as mesmas sensações, as mesmas dores, os mesmos discursos, o mesmo terror, a mesma sensação de iminência da morte. Caímos numa armadilha global. A memória que tínhamos dizia-nos que tudo era reversível e tinha remédio, e é essa crença que parece voltar sem fim. Expostos à catástrofe, desconectados e privados das nossas emoções, confinados, em curto-circuito, sobrevivemos e instalamo-nos de maneira a dar impressão que não é permanente. Desvitalizados, confusos, uma espécie de mortos-vivos sem desejo nem vontade sentimo-nos perdidos e não nos reconhecemos mais na irreversibilidade que alastra. 


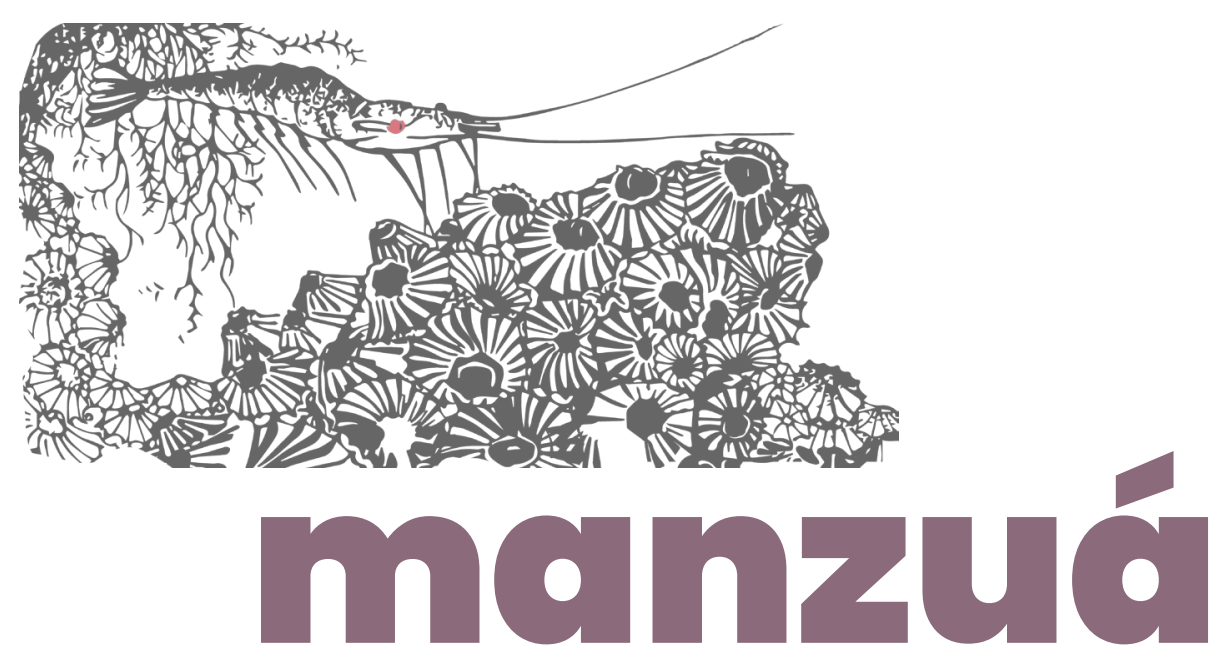

Ameaças naturais, sanitárias, ecológicas, políticas, económicas, éticas, medos íntimos ou planetários, muito há a temer. Entrámos numa espécie de rota de colisão que ainda assim parece insuficiente (se se acredita que é do choque ${ }^{2}$ que pode nascer o que nos força a pensar de maneira nova), porque não estamos a mudar ao ritmo necessário, não estamos a conseguir pensar com a velocidade que estes "tempos estranhos" exigem. Parece ter de ser uma onda de choque, um movimento tal que não possamos mais dizer ou fazer as mesmas coisas. Quando o choque não é suficiente caímos num "arbitrário sanguinolento" 3 e continuamos com os mesmos tiques lógicos, sociais, económicos e políticos, as mesmas falsas soluções.

Debatemo-nos quotidianamente com uma impotência do pensamento que se propaga e tem efeitos na acção e nos corpos. Uma "estranha petrificação" diz Deleuze. Se por instantes o mundo se suspendeu (nos primeiros meses de 2020) e o pensamento se encolheu e emperrou, foi só por um segundo, porque voltámos ao "mesmo" intolerável (ao que muita crítica global considera há muito obsoleto e mortífero). E, não é coisa de instantes, a constatação e a confirmação da "ruptura do elo do homem e do mundo" (Deleuze, 2006, p. 219), da ruptura e do estilhaçamento que tornam o intolerável uma coisa banal. A quebra do elo deixa-nos doentes e impotentes, dessolidariza-nos, e

"não é em nome de um mundo melhor ou mais verdadeiro que o pensamento apreende o intolerável neste mundo, é, ao contrário, porque este mundo é intolerável que ele já não pode pensar um mundo nem pensar-se a si próprio. O intolerável já não é uma injustiça maior, mas o estado permanente de uma banalidade quotidiana. O homem não é ele próprio um mundo diferente daquele em que experimenta o intolerável e se encontra imobilizado" (Deleuze, 2006, p. 221). 


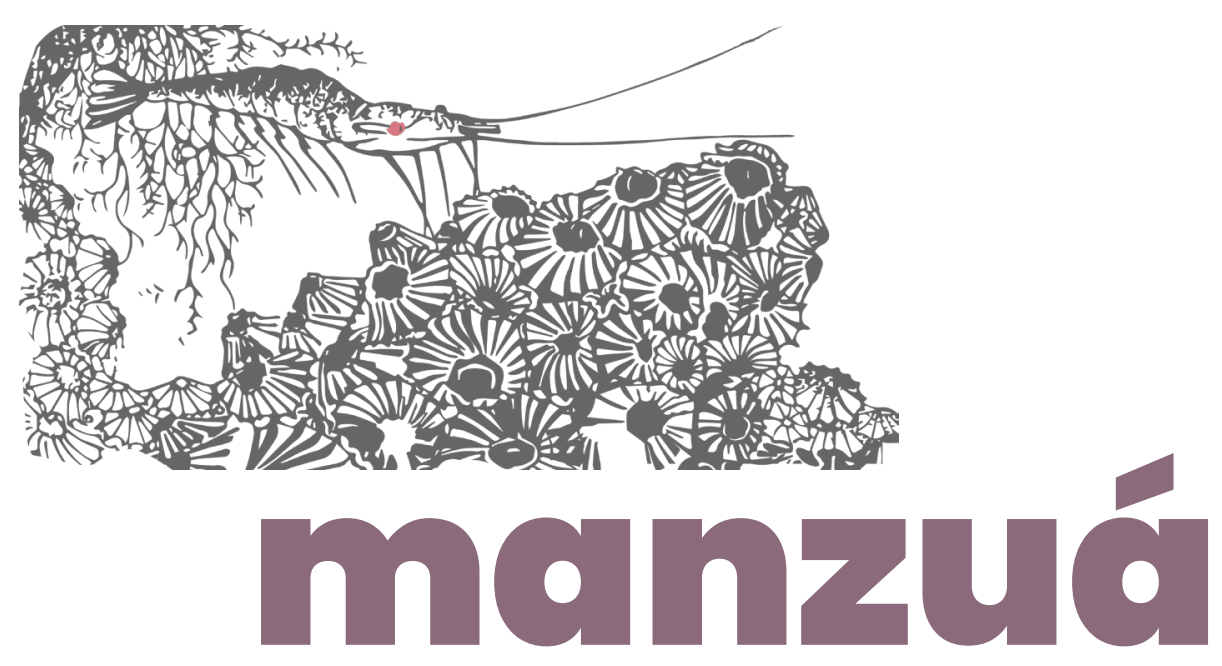

Mas o que foi que nos fez perder qualidades relacionais, o que foi que nos isolou?

O nosso corpo, como estes tempos e espaços confinados, fica também estranho e a terra aparece-nos na sua estranheza maior. Perdido o elo que nos liga a ela deixamos de a poder integrar e somos expulsos igualmente. Temos mais frio, mais calor, mais fome, mais sede, mais fadiga, mais desânimo, mais doenças, tudo é rápido demais para nos podermos adaptar. A empatia com o mundo desaparece, como a própria possibilidade de respirar, sufocamos na ausência do elo partido. Os nossos neurónios espelho não encontram interlocutor, tornam-se raros e inactivos. Os nossos corpos isolamse, desamparam-se. O nosso cérebro também muda. Escasseiam as sinapses, aumenta a indiferença, como aumentam os juízos negativos, a desconfiança, a impossibilidade de viver. Rejeita-se a terra que também nos rejeita e aumenta a sensação de terror, sentese o cheiro da morte.

Sem poder respirar, doentes, sem compreender e sem saber onde está a linha invisível e imperceptível que nos impede de sentir o mundo, e viver na Terra, ainda assim, temos de sair deste estado, desminar o terreno todo, enfrentar o absurdo no seu momento mais violento e perigosamente possível. Não é tarefa fácil, mas seremos obrigados, à evidência, a fazer a única coisa que há a fazer e que num momento crítico saberemos instantânea e vitalmente o que é: "penso na vida, todos os sistemas que eu poderei erguer nunca serão iguais aos meus gritos de homem ocupado a refazer a sua vida..."(Deleuze, 2006, p. 220). 


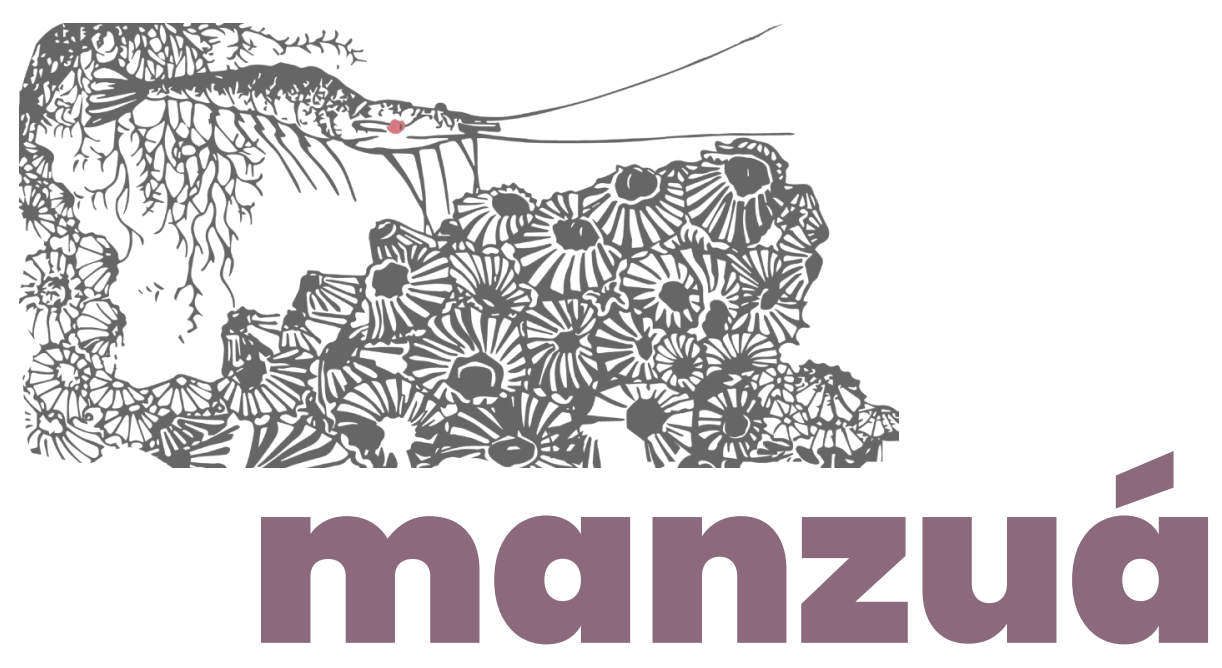

Vivemos o pior instante todos os dias, as sensações de horror não param (seja pela pandemia, seja pelas alterações climáticas). Estamos perante abomináveis sofrimentos que nos fazem pressentir a urgência da acção. Por isso não pára o estado de vigilância, de fechamento e controlo do meio que nos envolve. Ficamos fóbicos, hiperactivos, em estado de alerta permanente, irritáveis, com perturbações da atenção, obsessivos e disfuncionais. Procuramos evitar os perigos, mas deixamo-nos estar numa passividade em que nada mexe, numa espera estúpida e infinita, e aí mesmo desenvolvese e alastra a armadilha, porque sabemos de alguma maneira da nossa vulnerabilidade incontornável e parece que nada podemos fazer. Vítimas, também, da nossa própria violência, procuramos criar um mundo em que nos dizemos que estamos seguros, espécie de mundo paralelo onde julgamos que nos podemos refugiar. Mas esta vigilância permanente é esgotante e inútil. Precisamos de nos deslocar tanto, de produzir e consumir tanto e tão desigualmente? Todos os dias inventamos novos lixos e colonizamos a Terra com eles. A vida torna-se criticamente inominável.

A nossa angústia por não poder escapar à irreversibilidade da morte aumenta exponencialmente. E respondemos ao perigo, a qualquer coisa que não se consegue modificar, desconectandonos em todos os sentidos. Fazemo-lo diferentemente, orientandonos por coordenadas que não compartilhamos (as angústias dos mais novos não são as mesmas dos mais velhos), não exprimimos nem conseguimos comunicar verdadeiramente. A morte na sua irremediável ligação com a terra escapa-nos e estamos a perder tudo.

Porque também é verdade que já não acreditamos em nada, nem 


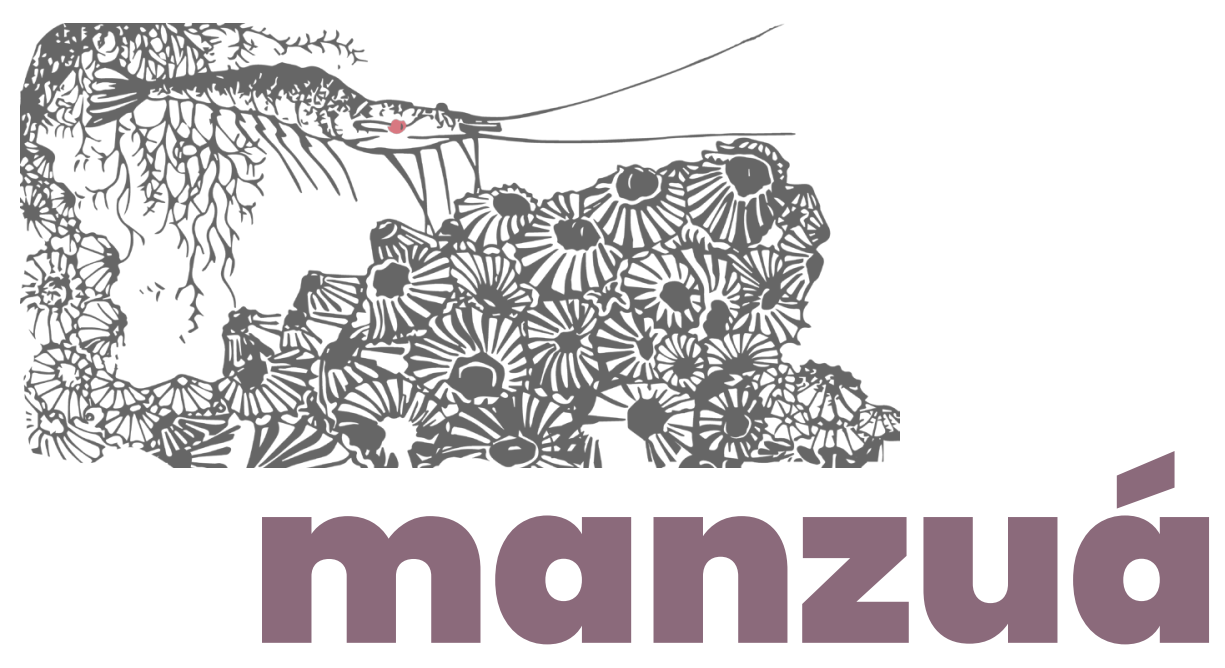

no que acontece, nem no que pensamos ou fazemos, ouvimos ou observamos. Uma espécie de alucinação global de imunidade, de protecção iluminada e louca, diz-nos que nada já nos diz respeito.

A terra, os corpos e as vidas persistem, mas perderam os seus centros. Tudo se mistura e dissolve. Quer dizer, no seio mesmo do que se transforma e muda, em aproximação ao elo que constitui a vida, a saúde e a evolução, surge a destruição mortífera e irreparável.

Para continuarmos a existir, o corpo (a Terra) tem de comprometerse numa continuidade de perseverança, numa duração, segundo os acasos dos fenómenos e dos acontecimentos, e que exige torções, desacelerações e deslocamentos, acima de tudo, uma "conversão da crença": "na nossa universal esquizofrenia temos necessidade de razões para acreditar neste mundo" (Deleuze, 2006, p. 222).

É simplesmente difícil de ver. O que não é imediatamente perceptível tem de ser intensamente vivido no corpo e não pode ser confundido com outras causas. Por isso há todo um trabalho de diagnóstico a fazer: distinguir a parte do passado e a parte do presente, no que está a acontecer, criar condições novas a cada instante e procurá-las em todas as escalas e em todos os contextos.

Talvez precisemos de fazer uma triagem dos medos (temos medo da vida, da morte, da natureza, dos outros, do vazio, de tudo) dos desejos destruidores, das ignorâncias e da estupidez, do que está misturado. Identificar e religar, renomear as situações, os acontecimentos, reconectar cada manifestação que permita dar coerência, recontextualizar e reintroduzir (novos comportamentos, novas reacções, emoções, empatias). Precisamos com muita urgência de fazer um trabalho de desminagem que nos permita viver, 


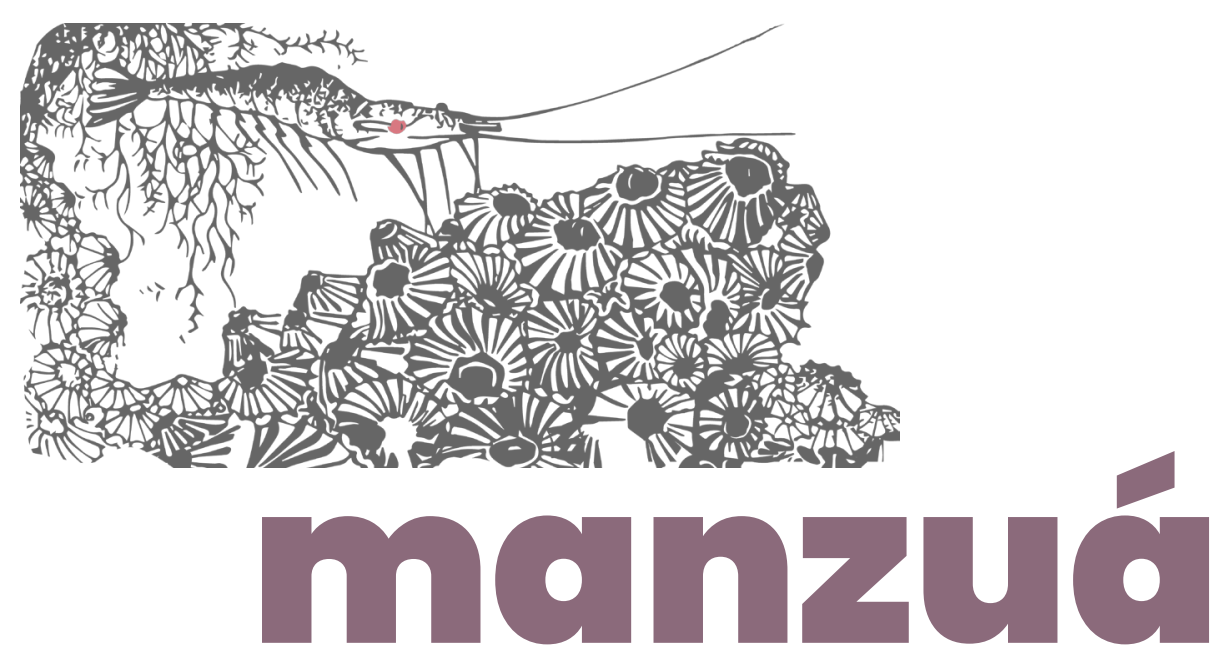

sair da sideração e voltar a entrar numa "continuidade da existência", fazer uma inversão de marcha com uma mudança profunda de coordenadas e dos próprios corpos.

Por enquanto, resistimos e duramos num impasse sem fim. E nada é linear ou completamente codificável, mas tudo se inscreve nos nossos corpos. Talvez precisemos mesmo de enviar outros sinais, fazer passar outras forças, mudar a nossa relação com a propriedade, com o que julgamos que é "nosso". Talvez seja necessário tornar a terra habitável e saudável para nos podermos aventurar nela.

O que nos dizem os mortos? O que nos passa pela cabeça quando encontramos a morte? Não conseguimos ver, mas já experimentámos tantas vezes e de tão diferentes maneiras (pequenas mortes, morte na literatura, na religião, na arte, no quotidiano, a morte dos outros): na ficção, na imaginação, na percepção, na memória. Sem carpir, sem acompanhamento colectivo dos mortos até ao seu último território, sem enterramento, abandonámos rituais milenares comuns a todas as culturas, normalizámos numa acção simplificada e asséptica o que antes passava por tantos passos, tantos gestos intermédios, tantos corpos. Os mortos dizem-nos que estamos a deixar só vazios e abstracções. É certo que a morte também se esquece, como a impotência também se pode tornar potência. O elo partido estendeuse cruelmente até aqui. Já não há mesmo território delimitado ou isolado, os restos dos corpos evaporam-se simplesmente no ar irrespirável. Utilizam-se esquemas de desaparecimento mais curtos e técnicas mais económicas de gestão de afectos e de espaços. A Terra não é a mesma. As cinzas espalham-se por todo o lado que é lugar nenhum.

Os vivos também se esquecem de si próprios, tornam-se biológica, 


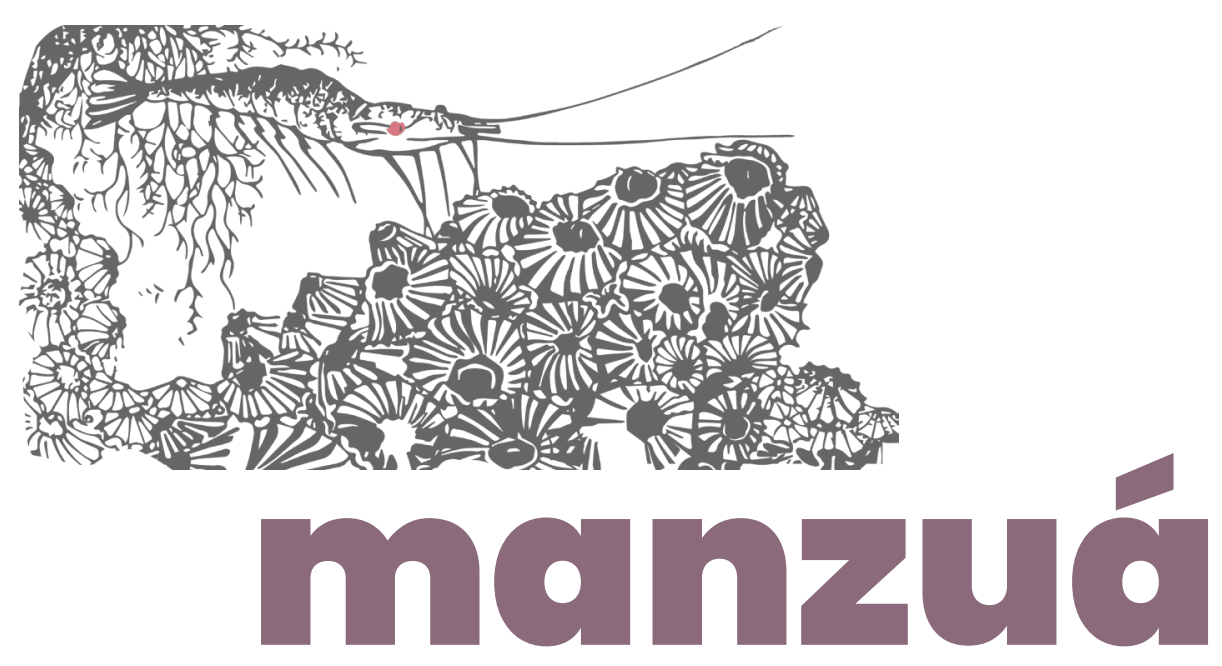

social e culturalmente mais assépticos e gelados. Vivem cada vez mais distantes, mais solitários, mais amnésicos e anónimos. As trocas são abstractas e virtuais, irreais. Não nos cruzamos na rua com corpos físicos, cruzamo-nos com ideias, opiniões. Até ao momento em que chocamos de frente com um vírus e um clima impossivel.

Atingidos de forma vívida podemos talvez começar a tocar noutras coisas mais reais, fazer passagens, saltar de um corpo para outro, habitar, contagiar, fazer alianças. Poderemos atravessar o intolerável, o desprezo, o conflito, o genocídio, o isolamento, os alheamentos, a doença e a morte. Não deixaremos que a desintegração maior se instale no quotidiano mais banal. "Qual é então a saída subtil?" pergunta Deleuze.

Não podemos deixar de nos questionar: de que precisamos mesmo para viver? Já não saberemos quais são as nossas necessidades? Até onde é a vida viável? Existem condições (biológicas, sociais, por exemplo) em que se torna intolerável, mortífera e sem retorno?

A terra pode bem permanecer para além de nós, porque não é uma matéria qualquer, mas para a continuarmos a habitar, para haver humanos na terra é necessário perceber bem os limites dos recursos e da destruição, se as alterações climáticas produzidas por nós atravessarem o limite das possibilidades é muito simples: não poderemos mais continuar a existir.

Preservar a vida da terra é preservar a nossa própria vida, o que nem sempre é fácil de ver. Talvez magicamente continuemos a pensar ou a querer pensar que a terra tem uma capacidade infinita para se autorregenerar. De cada vez que Ihe infligimos uma ferida ela curase. Seguindo esta lógica que já vimos muitas vezes funcionar, mesmo 


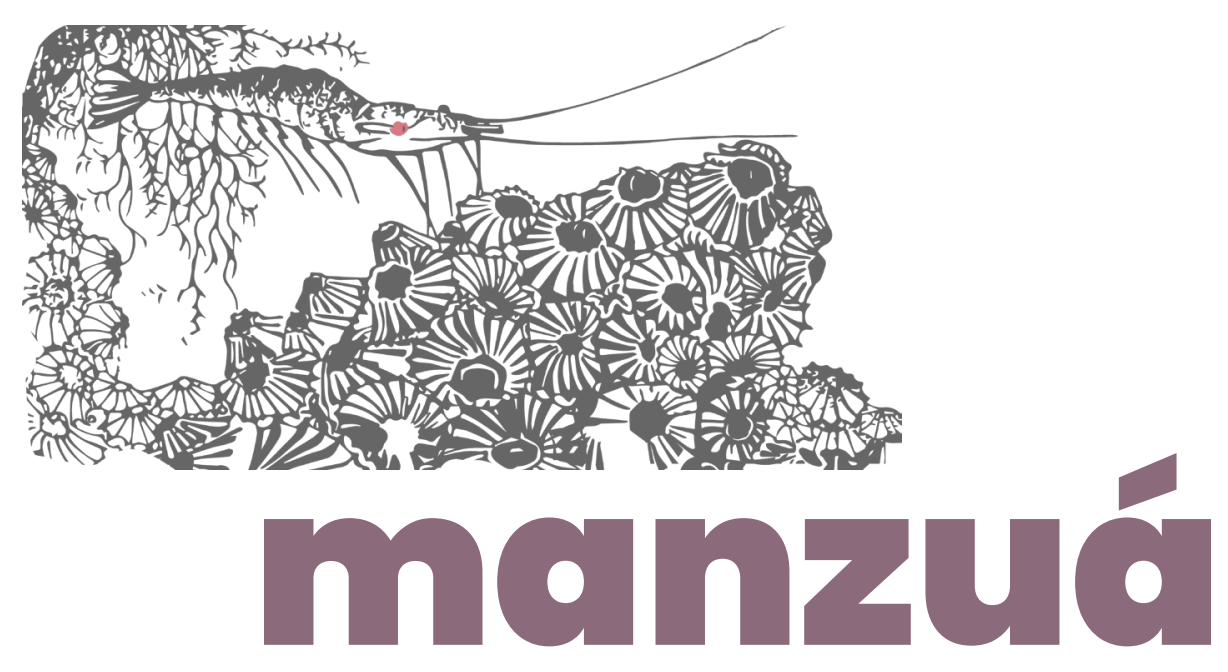

que a extensão e qualidade da ferida fosse ultrapassada, tudo funcionaria em favor da continuação da vida. Mas o pensamento mágico é insuficiente, existem feridas de morte. Temos então de fixar e respeitar certos limites para que os equilíbrios terrestres continuem. Compreendemo-nos na terra, incluindo-a necessariamente. Como um corpo é habitado e é ele próprio abrigo, local de vida. Se o destruirmos, é simples, extinguimo-nos e possivelmente levamos connosco os outos organismos vivos, a terra inteira.

Mas como mudar as perspectivas, os temperamentos, as vontades?

O que vivemos neste momento tornou-se quase instantaneamente mundial, a pandemia, as mudanças climáticas, o ar, a água, a comida, têm também esse grau de generalidade. O "não consigo respirar" somos todos nós a dizer! Não consigo alimentar-me, morro à sede, não tenho casa. Qualquer coisa não está a correr nada bem. E mesmo que alguns não o tenham vivido já experimentámos laboratorialmente o suficiente para o saber. Já temos uma longa experiência de reparação e regeneração. Já estabelecemos relações de causa efeito com os valores da poluição, descobrimos vacinas.

Não estamos à procura do segredo ou da essência da vida, não temos sequeruma fórmula adequada, umalgoritmo mágico. Masesforçamonos por compreender. Sabemos, no entanto, de características gerais, das suas formas de manifestação, reconhecemo-las. Certas propriedades dos seres vivos convêm-nos a todos. Plantas, animais, por muito diferentes que sejam, são todos atravessados por uma mesma corrente de matéria que Ihes permite respirar, alimentar-se e existir. Só a morte rompe este elo. A vida deixa de aí estar nesse instante. Todas as partes, todos os elementos se tornam subitamente estrangeiros uns aos outros, sem elos, sem solidariedade, não resistem 


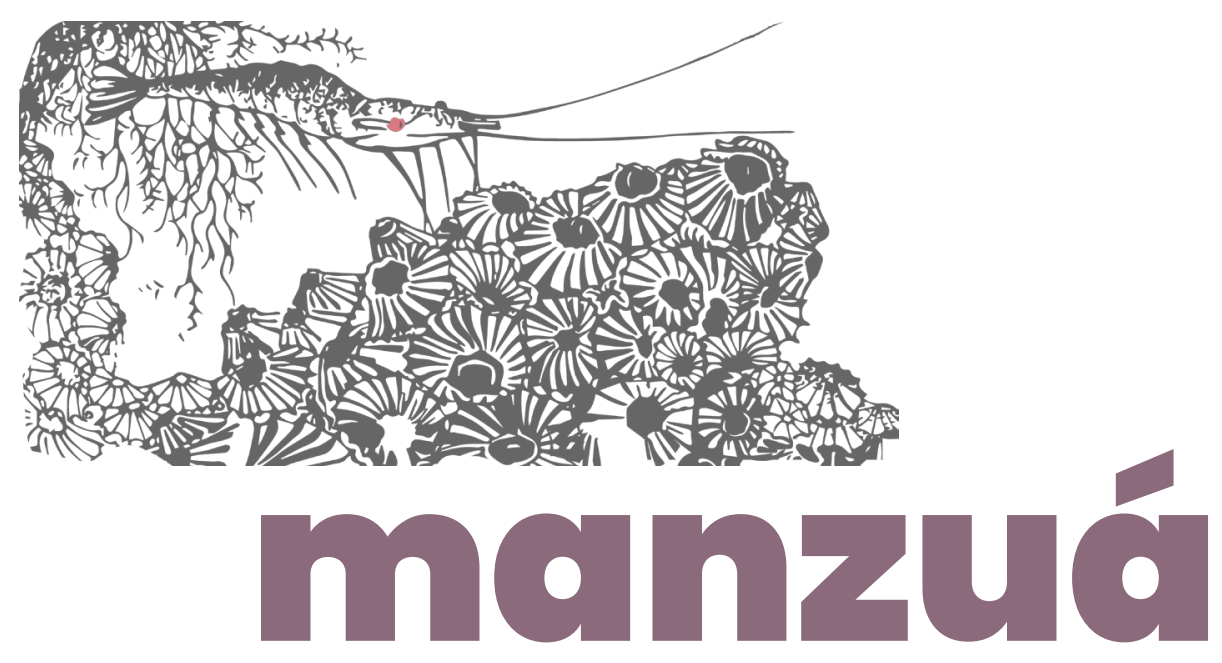

aos efeitos da dissolução. Para continuarmos a existir, os corpos - a Terra - têm de comprometer-se numa continuidade de conservação, agir juntos, numa duração, segundo os acasos dos fenómenos e dos acontecimentos, o que exige forças, "nada mais do que forças".

É preciso cruzar a mudança radical dos nossos hábitos e mentalidades com a transformação dos sistemas sociais, agindo juntos, acreditando noutra coisa -na Terra. Talvez seja a saída subtil sobre a qual se questiona Deleuze.

\section{Referência bibliográfica}

Deleuze, Gilles. A Imagem-Tempo, Cinema 2. Lisboa: Assírio\& Alvim, 2006.

(Endnotes)

1 Disponivel em: https://www.publico.pt/2020/09/08/p3/noticia/antonioguterres-ameaca-climatica-grave-pandemia-1930818

2 Ver Deleuze, 2006. Cf. Klein, Naomi. La stratégie du choc. La montée d'un capitalisme du désastre, Arles : Actes Sud, 2008.

3 Como se pode ver em Deleuze, 2006, p.213. 